\title{
Mutations in pathways depending on BRCA1 and BRCA2 may increase cancer risks from an environmental carcinogen
}

\section{Bernard Friedenson}

\author{
Author affiliation: Biochemistry and Molecular Genetics, College of Medicine, University \\ of Illinois Chicago, Chicago, IL \\ Correspondence to: Bernard Friedenson, Ph.D., Department of Biochemistry and Molecular \\ Genetics, University of Illinois Chicago, 900 S Ashland Ave, Chicago, IL 60607 (e-mail: \\ molmeddoc@Yahoo.com).
}


Carcinogens in our environment are officially classified according to whether they are carcinogenic to humans. They are then subdivided according to the strength of the evidence. Nonetheless, some groups of people may be more sensitive than others to environmental carcinogens. One of these groups may be people who inherit defective BRCA1 or BRCA2 genes ("breast cancer genes"). Women with this inheritance have high risks for breast /ovarian cancer as a group but individual risks within this group vary greatly [Begg et al, 2008]. This variation suggests that sensitivity to environmental carcinogens and/or contributions from additional genes may modify hereditary breast cancer risks. Defective BRCA genes also increase risks for cancers in organs other than breast and ovary but individuals may differ greatly in where these other cancers occur. These individual differences may implicate an increased sensitivity to environmental carcinogens in determining the tissue specificity of BRCA associated cancers. Additional genes may be involved as well [Friedenson, 2010].

BRCA1 and BRCA2 encode proteins required for complicated pathways to repair DNA damage. These pathways also require ATM and Fanconi proteins. Many studies show that carriers of mutations in such BRCA dependent pathways have difficulty repairing damage from DNA cross linking agents. Laboratory experiments with cells show that one of these cross linking agents is formaldehyde, a chemical that can connect strands of DNA to each other and to proteins in the vicinity of DNA. Chromosome breaks and loss of chromosomes may occur. If cells survive and are unable to correctly repair this damage, then the strands of DNA do not reproduce faithfully and the biological instructions on DNA may be misread.

Formaldehyde is a known carcinogen that seems everywhere. Widespread exposures occur during manufacture and use of resins, particle board, plywood, leather goods, paper, pharmaceuticals, cosmetics, baby bath products, nursery furniture, and 
food. Annual dietary intake has been calculated as about 4,000 mg [Owen et al, 1990]. Paints, varnishes, floor finishes, tobacco smoking, auto exhaust and organic combustion all release formaldehyde. Formaldehyde enters water from industrial wastes and may occur as a by-product of water disinfection. Formaldehyde goods constitute $5 \%$ of US gross national product with production of nearly 5 million tons in 2003 [Zhang et al, 2010].

In the general population, the World Health Organization's International Agency for Research on Cancer (IARC) classifies formaldehyde as a direct human mutagen and a known carcinogen proven to cause nasopharyngeal cancers and myeloid leukemia [Baan et al, 2009]. Myeloid leukemia is a malignancy of the white cells important in the first defenses against disease causing microorganisms. Epidemiological evidence found that embalming was significantly associated with an increased risk for myeloid leukemia, with significant trends for cumulative years of embalming ( $p$ trend $=0.020$ ) and for increasing peak formaldehyde exposure ( $p$ trend=0.036) [Baan et al, 2009].

For several years, doubts were raised about whether formaldehyde caused leukemia. Environmental formaldehyde is a water soluble gas and it was not clear how inhaling it could lead to white cell malignancies. Yet DNA-protein cross links formed by formaldehyde routinely served as a measurement for its concentration within cells. Then chromosome breaks and leukemia-specific chromosome changes [Zhang et al, 2010; Baan et al, 2009] were found in precursors of myeloid white cells. Nasal epithelium in rats had been known to contain stem cells capable of forming myeloid white cell producing tissue [National toxicology program, 2010]. This then provided a plausible way carcinogenic damage to nasal stem cells from inhaled formaldehyde could develop into myeloid leukemia. This possibility is further supported by the elevated incidence rate of leukemia and other hematological malignancies in individuals with nasopharyngeal cancer. Identification of genetic susceptibility loci for nasopharyngeal cancer found these loci were also all involved in leukemogenesis. This suggests a partially shared pathogenic mechanism between hematologic malignancy and nasopharyngeal cancer [Bei et al, 2010]. 
Endogenous formaldehyde is produced by normal metabolism but endogenous formaldehyde is detoxified by enzymes in dedicated pathways unrelated to BRCA1/2: glutathione-dependent formaldehyde dehydrogenase (ADH3) and aldehyde dehydrogenases. Depleting these enzymes or overwhelming them at high formaldehyde concentrations favors DNA-protein cross linking. The distribution, ontogeny, and regulation of ADH3 have important implications for the clearance of endogenous and exogenous formaldehyde [Thompson et al, 2009]. DNA cross links, chromosome breaks and chromosome abnormalities would be favored by saturating formaldehyde processing enzymes with environmental formaldehyde.

Repairing such complex DNA damage requires homologous recombination pathways [Nakano et al, 2007] and repair pathway coordination mediated by BRCA1, BRCA2 (Fanconi protein D1), and 12 other Fanconi proteins. Inherited mutations interfere with these repairs and are associated with leukemias, especially myeloid leukemias. This association is quite clear for some homozygotes. Six children with biallelic BRCA2 mutations all developed leukemia at median age 2.2 years, with 4 of 6 developing acute myeloid leukemia (AML) [Wagner et al, 2004]. A review of all biallelic BRCA2 mutation patients found a $79 \%$ cumulative probability of leukemia (primarily AML) by age 10 years [Alter et al, 2007]. In Fanconi anemia homozygotes, summary relative risks for AML were 703.3 [363.7-1354.5] [Friedenson, 2007].

With more limited evidence, the IARC also implicated formaldehyde in the very rare cancer, sinonasal cancer [Baan et al, 2009; National Toxicology Program, 2010]. The annual incidence of nasal tumors in the United States is estimated to be less than 1 in 100,000 people per year with females having half the incidence of males. Nasal sinus cancer has been reported in heterozygous BRCA1 mutation carriers [Thompson et al, 2002]. Two nose cancers were found in heterozygous BRCA2 carriers [Breast cancer linkage consortium, 1999]. Both the BRCA1 and BRCA2 studies contained far less than 100,000 people, primarily women; so risks for cancers of the nose were 
elevated. However, cancers involving the nose were grouped among "other cancers", preventing relative risk calculations.

The Fanconi core subcomplex (containing Fanconi proteins-A, B, C, E, F, G, L, and FAAP100) promotes translesion synthesis by error tolerant polymerases. Translesion synthesis probably keeps stalled replication forks from breaking, thereby maintaining chromosome continuity [Thompson and Hinz, 2009]. Ridpath et al [2007] assessed the DNA damage response to plasma formaldehyde using chicken DT40 cells with targeted mutations in various DNA repair genes. DT40 mutants deficient in the BRCA/Fanconi pathway, homologous recombination, or translesion DNA synthesis were hypersensitive to formaldehyde. The most sensitive mutants were deficient in BRCA2 or Fanconi protein-D2. Human cells deficient in core complex Fanconi proteins $-C$ and $-G$ were also hypersensitive to plasma formaldehyde [Ridpath et al, 2007].

In addition to requiring BRCA and Fanconi proteins, complex DNA damage and replication fork stalling also activate ataxia telangiectasia mutated (ATM) and ataxia telangiectasia and Rad3-related (ATR) kinases, and downstream checkpoint kinases $\mathrm{CHK} 2$ and $\mathrm{CHK} 1$. Hereditary cancer-prone conditions are known that relate to inherited defects in some of these genes. In 1976 it was widely recognized that ataxia telangiectasia patients (homozygous ATM mutation) are very likely to develop cancers that have some association to formaldehyde exposure. Hematologic malignancies that caused premature deaths in blood relatives from 27 families of ataxia-telangiectasia patients included Hodgkins disease, monocytic leukemia, acute myeloid leukemia, and lymphatic leukemia. Five deaths from leukemias and lymphomas occurred below age 45 in comparison to 1 expected death [Swift et al, 1976]. The overall excess cancer risk in heterozygous ATM mutation carriers younger than 50 years of age appeared to be due to several different cancer types including nasopharyngeal cancer in the 6-year-old brother of an ataxia-telangiectasia patient; this was the only juvenile cancer in a relative [Thompson et al, 2005]. 
Recently, the President's Cancer Panel [2008-2009] protested that preventive action is not taken when uncertainty exists about potential harm from a chemical, because the US regulatory approach demands that a hazard be incontrovertibly demonstrated. It is now incontrovertible that formaldehyde increases risks for leukemias. Evidence is also strong that formaldehyde causes some types of DNA damage in humans that are known to require repairs mediated by BRCA1/2 containing pathways. Disabling BRCA1/2 related DNA repair processes prevents repair of formaldehyde related DNA damage in laboratory cells. DNA-protein cross links result in the accumulation of DNA double strand breaks in homologous recombination-deficient but not homologous recombination -proficient cells. Homologous recombination repairs require ATM, BRCA1/2 and Fanconi proteins. ATM heterozygotes have increased risks for some leukemias that have been linked to formaldehyde in normal individuals. Weaker evidence suggests increased risk for rare nasopharyngeal or sinonasal cancers in heterozygous BRCA1/2 mutation carriers and in ATM mutation carriers.

It should be stressed that the above evidence is not incontrovertible proof that formaldehyde causes excess hematologic cancer risks in mutation carriers that goes beyond formaldehyde cancer risks in normal individuals. There is virtually no information on its effect on breast and ovarian cancer risk in mutation carriers. However, formaldehyde is a pervasive environmental carcinogen that is theoretically more likely to cause malignancy in carriers of mutations that disable protective repair pathways. Because of this uncertainty it is prudent for mutation carriers to immediately avoid formaldehyde, especially high level exposure. The EPA recommends four basic "Steps to Reduce Exposure" for everyone.

Use "exterior-grade" pressed wood products (lower-emitting because they contain phenol resins, not urea resins).

Use air conditioning and dehumidifiers to maintain moderate temperature and reduce humidity levels. 
Increase ventilation, particularly after bringing new sources of formaldehyde into the home.

Ask about the formaldehyde content of pressed wood products, including building materials, cabinetry, and furniture before you purchase them.

\section{Bibliography}

Alter B, Rosenberg P. Brody L. Clinical and molecular features associated with biallelic mutations in FANCD1/BRCA2. J Med Genet 2007; 44:1-9.

Baan R, Grosse Y, Straif K, Secretan B, El Ghissassi F, Bouvard V, BenbrahimTallaa L, Guha N, Freeman C, Galichet L, Cogliano V; WHO International Agency for Research on Cancer Monograph Working Group. A review of human carcinogens--Part F: chemical agents and related occupations. Lancet Oncol. 2009;10(12):1143-4.

Begg C, Haile R, Borg A, Malone K, Concannon P, Thomas D, Langholz B, Bernstein L, Olsen J, Lynch C, Anton-Culver H, Capanu M, Liang X, Hummer A, Sima C, Bernstein J. 2008; Variation of Breast Cancer Risk Among BRCA1/2 Carriers JAMA. 299(2):194-201

Bei JX, Li Y, Jia WH, Feng BJ, Zhou G, Chen LZ, Feng QS, Low HQ, Zhang H, He F, Tai ES, Kang T, Liu ET, Liu J, Zeng YX. A genome-wide association study of nasopharyngeal carcinoma identifies three new susceptibility loci. Nat. Genet. 2010 Jul;42(7):599-603.

Friedenson $\mathrm{B}$. The BRCA1/2 pathway prevents hematologic cancers in addition to breast and ovarian cancers. 2007; BMC Cancer 7:152. 
Friedenson B, A theory that explains the tissue specificity of BRCA1/2 related and other hereditary cancers. J. Med. Med. Sci. 2010;1(8): 372-384.

Nakano T, Katafuchi A, Matsubara M, Terato H, Tsuboi T, Masuda T, Tatsumoto T, Pack SP, Makino K, Croteau DL, Van Houten B, lijima K, Tauchi H, Ide H. Homologous recombination but not nucleotide excision repair plays a pivotal role in tolerance of DNA-protein cross-links in mammalian cells. J Biol Chem. 2009; 284(40):27065-76.

National Toxicology Program. Final Report on Carcinogens. Background Document for Formaldehyde. Rep Carcinog Backgr Doc. 2010 Jan;(10-5981):i512.

Owen B, Dudney C, Tan E, Easterly C. Formaldehyde in drinking water: comparative hazard evaluation and an approach to regulation. Regulatory Toxicology and Pharmacology. 1990; 11(3):220-36.

Ridpath J, Nakamura A, Tano K, Luke AM, Sonoda E, Arakawa H, Buerstedde JM, Gillespie DA, Sale JE, Yamazoe M, Bishop D, Takata M, Takeda S, Watanabe M, Swenberg JA, Nakamura J. Cells deficient in the FANC/BRCA pathway are hypersensitive to plasma levels of formaldehyde. Cancer Res. 2007; 67(23):11117-22.

Swift M, Sholman L, Perry M, Chase C. Malignant neoplasms in the families of patients with ataxia-telangiectasia. Cancer Res. 1976; Jan;36(1):209-15.

The Breast Cancer Linkage Consortium. Cancer risks in BRCA2 mutation carriers. J. Natl Cancer Inst. 1999; 91: 1310-1316.

Thompson C, Sonawane B, Grafstrom R. The Ontogeny, Distribution, and Regulation of Alcohol Dehydrogenase 3: Implications for Pulmonary Physiology. Drug metabolism and disposition. 2009;37:1565-1571.

Thompson D, Easton DF; Breast Cancer Linkage Consortium. Cancer Incidence in BRCA1 mutation carriers. J Natl Cancer Inst. 2002;94(18):1358-65 
Thompson L, Hinz J. Cellular and molecular consequences of defective Fanconi anemia proteins in replication-coupled DNA repair: mechanistic insights. Mutat Res. 2009; 668(1-2):54-72.

Wagner JE, Tolar J, Levran O, Scholl T, Deffenbaugh A, Satagopan J, Ben-Porat L, Mah K, Batish SD, Kutler DI, MacMillan ML, Hanenberg H, Auerbach AD. Germline mutations in BRCA2: shared genetic susceptibility to breast cancer, early onset leukemia, and Fanconi anemia. Blood. 2004; 103(8):3226-9.

Zhang L, Tang X, Rothman N, Vermeulen R, Ji Z, Shen M, Qiu C, Guo W, Liu S, Reiss B, Freeman LB, Ge Y, Hubbard AE, Hua M, Blair A, Galvan N, Ruan X, Alter BP, Xin KX, Li S, Moore LE, Kim S, Xie Y, Hayes RB, Azuma M, Hauptmann M, Xiong J, Stewart P, Li L, Rappaport SM, Huang H, Fraumeni JF Jr, Smith MT, Lan Q. Occupational exposure to formaldehyde, hematotoxicity, and leukemia-specific chromosome changes in cultured myeloid progenitor cells. Cancer Epidemiol Biomarkers Prev. 2010; 19(1):80-8. 